\title{
A compelling case of postpartum symmetrical peripheral gangrene
}

\author{
Mehmet Kızılay॰
}

Department of Cardiovascular Surgey, Somalia - Turkey Recep Tayyip Erdoğan Training and Research Hospital, Mogadishu, Somalia

\begin{abstract}
Symmetrical peripheral gangrene is one of the very rare problems that is usually secondary to intense inotropic therapy in critically ill patients, but also due to use of ergot alkaloids or sepsis in the postpartum period. We present a case of symmetrical peripheral gangrene developed in lower extremities of a woman in postpartum period ten days after discharge from hospital to which she was admitted and transfused 2 units of erythrocyte suspension due to significant bleeding following delivery conducted at home by an unskilled midwife in Mogadishu, Somalia. After pregnancy, whatever the cause, if developing symmetrical peripheral gangrene is not diagnosed in time and not treated as early as possible can cause limb loss and disability. Detection and investigation of this condition will also be enlightening for the mechanisms for ischemia and subsequent recuperation of circulation.
\end{abstract}

Keywords: Ergotalkaloids, postpartum, symmetrical peripheral gangrene

D istal symmetrical peripheral gangrene, which is not a classical peripheral vascular disease, is one of the rare cases seen after delivery. Whether it is because of physiological changes in the peripheral vascular system during pregnancy (increased plasma volume, decreased plasma osmolality and decreased peripheral resistance) that actually obscure a severe vasospasm is not fully understood. However, ergot alkaloids used during childbirth, sepsis during or after delivery, and inotropic agents used in the treatment of septic shock are thought to be associated with distal symmetric peripheral gangrene $[1,2]$.

\section{CASE PRESENTATION}

A 34-year-old P2L2 female patient underwent 2 intermittent blood transfusions at the health center, where she was admitted for significant bleeding following delivery by an unskilled midwife at home in Somalia, where traditional methods are often preferred.The patient was discharged after controlling the bleeding and was admitted to our hospital 10 days later due to coldness in the feet, bruising on the skin, pain and progressive gangrene. The patient was hospitalized for examination and treatment. The general condition of the patient was good; vital signs were recorded as stable. All peripheral pulses were palpable. Black, wet-looking dried skin images were present on both dorsal and plantar sides of the feet (Fig. 1a and 1b). On abdominal examination a well contracted uterus was felt. There was no prior history of intermittent claudication, cold or heat intolerance, tobacco smoking, collagen vascular disease or similar family history.

Laboratory data at the time of admission showed 


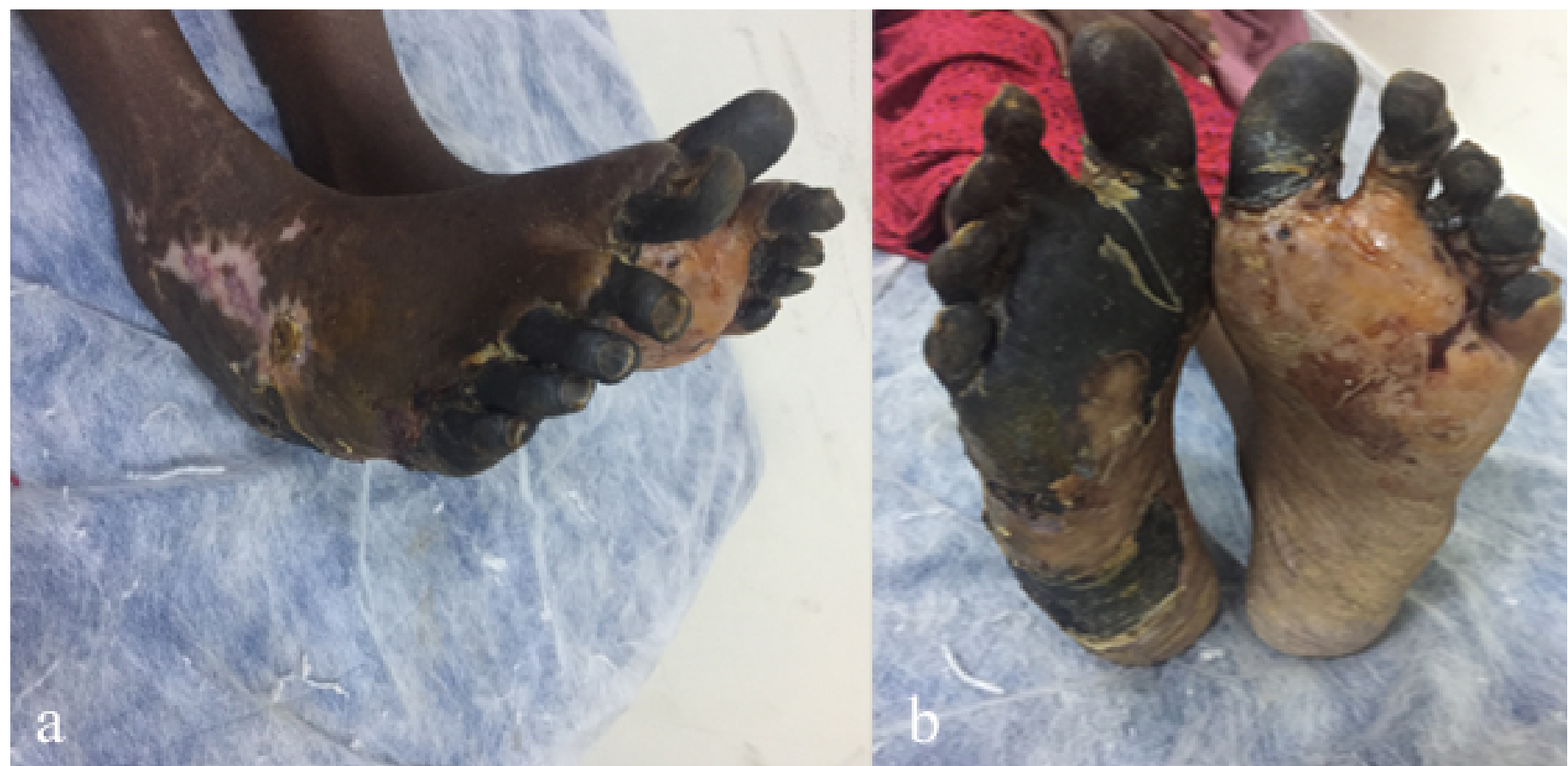

Fig. 1. Postpartum 10th day extremity appearance $(a, b)$.

that hemoglobin $(\mathrm{Hb})$ was $9.9 \mathrm{~g} / \mathrm{dL}$; hematocrit $(\mathrm{Hct})$ $32.8 \%$; white blood cell (WBC) count $12.470 / \mathrm{mm} 3$; platelet count $674.000 / \mathrm{mm} 3$; liver function tests: total serum bilirubin $8 \mathrm{mg} / \mathrm{dL}$, alanine aminotransferase (ALT) $30 \mathrm{U} / \mathrm{L}$, aspartate aminotransferase (AST) 37
$\mathrm{U} / \mathrm{L}$; and kidney function tests: serum creatinin 0.65 $\mathrm{mg} / \mathrm{dL}$ and blood urea $27 \mathrm{mg} / \mathrm{dL}$. Total protein was 6.9 $\mathrm{g} / \mathrm{dL}$; albumin $3.3 \mathrm{~g} / \mathrm{dL}$, and CRP $41.6 \mathrm{mg} / \mathrm{dL}$. On sepsis work-up, her blood and urine cultures were sterile. On clotting screen prothrombin time (PT) was $12 \mathrm{sec}-$
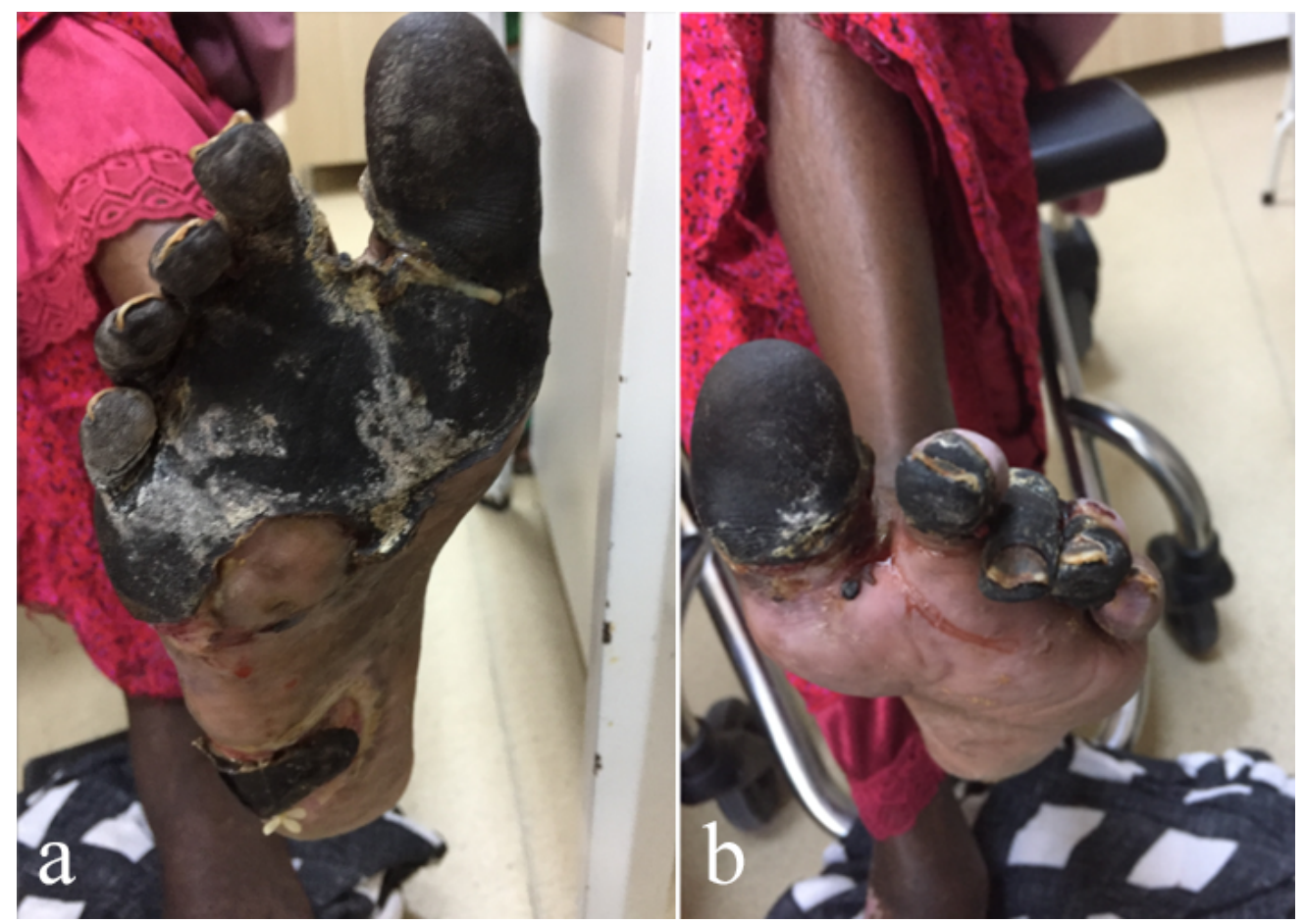

Fig. 1. Postpartum 40th day right (a) and left (b) extremity appearance. 
onds and partial thromboplastin time test kaolin (PTTK) 32 seconds. Lipid profile was as follows: Serum cholesterol $153 \mathrm{mg} / \mathrm{dL}$, serum triglyceride 173 $\mathrm{mg} / \mathrm{dL}$, high-density lipoprotein cholesterol (HDL) 40 $\mathrm{mg} / \mathrm{dL}$, low-density lipoprotein cholesterol (LDL) 113 $\mathrm{mg} / \mathrm{dL}$. Amilase was $37 \mathrm{U} / \mathrm{L}$, lipase $25 \mathrm{U} / \mathrm{L}$, total $\mathrm{IgE}$ $357.5 \mathrm{IU} / \mathrm{ml}$, alkaline phosphatase (ALP) $224 \mathrm{U} / \mathrm{L}$, gamma glutamyltransferase (GGT) $132 \mathrm{U} / \mathrm{L}$, lactate dehydrogenase (LDH) $436 \mathrm{U} / \mathrm{L}$, antistreptolysin $\mathrm{O}$ (ASO) $326 \mathrm{IU} / \mathrm{ml}$, rheumatoid factor (RF) $21 \mathrm{IU} / \mathrm{ml}$. Color doppler ultrasound of the lower extremity vessels revealed three-phasic character of normal circulation. The biopsy of the gangrene tissue was consistent with epidermal necrosis. Medical treatment consisting of broad spectrum antibiotics, low molecular weight heparin and pentoxifylline was initiated. The necrotic appearance of the feet limited itself with treatment (Fig. 2a and 2b). The patient underwent regular follow-up after discharge and underwent amputation distaltothe the right ankle. The lesion on the left toes limited itself by auto amputation.

\section{DISCUSSION}

The development of postpartum gangrene during pregnancy has been reported, sporadically. However, in most of these, it has been emphasized that the existing peripheral vascular disorder may be caused by the use of ergot alkaloids used in relieving pain symptoms [1]. In another study, they found a relationship between the symmetrical peripheral gangrene after sepsis [3]. In addition, it has been mentioned that high doses of dopamine and noradrenaline, which can be used for inotropic support, may lead to decreased ischemia, and ultimately leading to gangrene, together with vasoconstriction $[4,5]$. However, the extent of the effect of the use of these drugs has not been specified. It has not been denied that they may be accompanied by the contribution of common intravascular coagulation and development of disseminated intravascular coagulation (DIC) [6].

In our patient's history, she had no previous signs and symptoms of peripheral vascular disease, and she did not experience any similar complaints or discomfort after her previous delivery. In the postpartum period, symmetrical gangrene occurred in the distal part of both lower extremities 10 days after blood transfusion, which was not expected. It is stated that sporadic cases of distal gangrene can be seen after ergot alkaloids used for painless delivery and postpartum sepsis due to various reasons. In our case, the presence of blood transfusion historymay suggest the effect of transfusion. Although a variety of conditions have been observed from simple redness to renal failure and more severe conditions due to transfusion reaction, such cases of symmetrical gangrene have not been reported. A herbal or chemical agent that may have been used in traditional births may also play a role in the development of gangrene in our case.

\section{CONCLUSION}

In cases of peripheral gangrene developing postpartum due to various reasons, especially if the cause cannot be determined as in our case, having high index of suspicion during the onset of symptoms would prevent the necrosis to reach more proximal segments of the limb, and thus limb would be saved with early and proper institution of medical treatment. In addition, the detection and examination of this condition will be enlightening for the pathophysiological mechanisms of ischemia and the subsequent restoration of circulation.

\section{Informed consent}

Written informed consent was obtained from the patient for publication of this case and any accompanying images.

\section{Conflict of interest}

The author declared that there are no potential conflicts of interest with respect to the research, authorship, and/or publication of this article.

\section{REFERENCES}

1. Dam AK, Mishra JC. Managing ergot-induced gangrene: the anesthesiologist as a key player. Anesth Analg 2002;95:409-10. 2. Ghosh SK, Bandyopadhyay D, Ghosh A. Symmetrical peripheral gangrene: a prospective study of 14 consecutive cases in a tertiary-care hospital in eastern India. J Eur Acad Dermatol Venereol 2010;24:214-8.

3. Kampmeier TG, Rehberg S, Westphal M, Lange M. Vasopressin in sepsis and septic shock. Minerva Anestesiol 
2010;76:844-50.

4. Dong J, Zhang L, Rao G, Zhao X. Complicating symmetric peripheral gangrene after dopamine therapy to patients with septic shock. J Forensic Sci 2015;60:1644-6.

5. Winkler MJ, Trunkey DD. Dopamine gangrene: association with disseminated intravascular coagulation. Am J Surg 1981;142:588-91.

6. Gibbs NM, Oh TE. Nitroglycerine ointment for dopamine induced peripheral digital ischaemia. Lancet 1983;2:290. 